\title{
Powerful Vocabulary Acquisition through Texts Comparison
}

\author{
Mohammad Reza Hasannejad (Corresponding author) \\ Department of English Language and Literature, Iranshahr Branch, Islamic Azad University, Iranshahr, Iran \\ E-mail: m-hassannejad@iau-ahar.ac.ir \\ Hamid Bahador \\ Department of English Language and Literature, Iranshahr Branch, Islamic Azad University, Iranshahr, Iran \\ Seyyed Ali Kazemi \\ Department of English Language and Literature, Yasuj Branch, Islamic Azad University, Yasuj, Iran
}

Received: 08-09-2014

doi:10.7575/aiac.ijalel.v.4n.2p.213
Accepted: 13-11-2014

Published: 01-03-2015

\begin{abstract}
This study aimed to investigate if dual version reading comprehension had a positive effect on Intermediate EFL students' general vocabulary acquisition, receptive and productive knowledge of vocabulary and students' synonymous power of words. Two groups were selected - the experimental group and the control group. The study included: (1) four pretests (2) the dual version reading comprehension, and (3) four posttests. It was found that there was no significant difference between the two groups of students on the pretests. However there was a significant difference between the two groups of the students on the posttests. Overall, the dual version reading comprehension vocabulary-learning made the experimental group learners outperformed the control groups in terms of their performance on four types of vocabulary tests. This indicates that students following dual version reading comprehension were more successful in vocabulary acquisition, and developing their receptive knowledge of vocabulary, transferring their receptive knowledge in to the productive knowledge and enhancing the memorization of the synonymous words.
\end{abstract}

Key words: Dual version reading comprehension, Receptive knowledge, Productive knowledge, Synonymous power

\section{Introduction}

English is certainly a worldwide language. In the process of learning English, it is almost certainly that vocabulary plays a key role. Research has consistently indicated that one's language proficiency is directly related to his or her vocabulary knowledge (Kelly, 1991). Wilkins (1972) also claimed that, "Without grammar very little can be conveyed; without vocabulary nothing can be conveyed" (p. 111). Since vocabulary plays a key role for second language learners, how teachers can improve students' word knowledge is an important question. Vocabulary learning and teaching are current issues, but in the past, they were ignored and did not get sufficient consideration. With regards to vocabulary's place in ESL instruction, Coady (1993) cited that throughout the history of the grammar-translation methods and in the early phase of the direct method, vocabulary was considered of as the main element in language learning.

However, with the strong emphasis on grammar rules throughout the grammar-translation era, vocabulary did not receive enough attention and was only employed to explain grammatical rules (Schmitt, 2000). In such a situation, Schmitt adds that language learning only focused on the use of examples rather than entire passages. He also cited that learners were mostly expected to be taught words through bilingual word lists, so the bilingual dictionaries roles became highlighted. In the time of the direct method, the focus was shifted to stress the role of exposure to oral language (Schmitt, 2000) and learners tried to learn new words through their interaction with others.

Around the advent of the audio-lingual methods, oral skills were also emphasized and the role of vocabulary was downplayed because vocabulary domain was mostly considered necessary for sentence drills (DeCarrico, 2001; Schmitt, 2000). With the appearance of the communicative approaches in the 1970s, teaching focused on the proper use of language varieties, and language became regarded as a device of discourse (Coady, 1993). In other words, language teaching focus at that time shifted from sentence-level forms towards discourse-level functions (DeCarrico, 2001). The position of vocabulary was considered as a support for functional language use .Moreover, the acquisition of a second language was considered as a phenomenon which is similar to first language acquisition. Therefore, vocabulary was supposed to be able to take care of itself when learners come to learn a second language (Coady, 1993). Step by step, there came the advance of natural approaches, which emphasized following L1 learning conditions and causing L2 learners acquire language skills naturally. But it seemed that natural learning would not suggest enough literacy skills to deal with academic demands.

The above- cited discussion caused an important question: Should we teach vocabulary naturally or formally? It is not important how to teach vocabulary, enough attention is needed. According to Nation (1990), giving attention to vocabulary is inevitable, and teaching must involve required vocabulary even when the teacher employs communication-directed 
approaches to language teaching. Krashen (1989) also stated that in the process of second language acquisition (SLA), vocabulary plays a crucial role when learners develop the four skills of listening, speaking, reading, and writing. Due to these reasons, vocabulary instruction is an important issue of discussion.

Vocabulary acquisition has long been considered as a fundamental factor which influences ESL/EFL but it is an area that is often ignored. Zimmerman (1997) states that "the teaching and learning of vocabulary has been undervalued in the field of second language acquisition (SLA) throughout its varying stages and up to the present day" (p. 5). Paribakht and Wesche (1997) also argue the issue of vocabulary acquisition should receive a lot of attention from researchers or teachers, as "it is still far from clear how learners acquire vocabulary or how it can best be taught"(p. 174). It should be pointed out that yet not until recently did the issue of vocabulary acquisition through different types of dictionaries, various input-output activities, contextualized/decontextualized, incidental /international and form-focused/non-form focused vocabulary acquisition receives a lot of attention.

Several researchers in the field of vocabulary acquisition (Laufer, 1991, 1997; Nation, 1993; Ridgway, 1997; Smith, 1998) also discovered that vocabulary knowledge was directly related to reading comprehension. Given the close relationship between ESL/EFL learners' vocabulary domain and their capability to realize English readings, researchers tried to find out ways to efficiently improve students' acquisition and retention of learned words. Many techniques of direct vocabulary instruction have been reported effective through such attempts, including glosses (Hulstijn, 1992; Watanabe, 1997), mnemonic devices (Beaton, Gruneberg \& Ellis, 1995), morphological and syntactic analysis (Anglin, 1993; Bauer \& Nation, 1993; Nation, 1994) and etc. Although researchers agreed that reading is one important element to vocabulary acquisition, the usefulness and effectiveness of this approach are questionable, mainly when compared with reading plus supplementary word-focused activities (Laufer \& Hill, 2000; Paribakht \& Wesche, 1997).

In view of the fact that more than two decades of findings on the above- cited techniques are far from conclusive and especially due to the above-cited reasons, the plausible relationship between reading and vocabulary acquisition approach has yet been under attack. In the current study, the researcher wished to add to the extant database on the relative effectiveness of reading by introducing dual version reading comprehension in which one basic and advanced version of the same text will be provided. Dual version reading comprehension will help us to make a comparison between the basic and advanced versions of the similar texts in order to comprehend the texts better. So it will lead learners to have input passages which are more comprehensible and also devote more time for them. Therefore, through dual version reading comprehension, vocabulary learning occurs in the context and it provides learners with richer word usage and meaning than traditional vocabulary instruction. This means that students not only learn words in context but also know how words are used in context. In this way, they can better know the usage of the word, rather than only learn the word itself.

Four research questions are raised as follows:

\subsection{Research questions}

1. Does dual version reading comprehension improve Iranian EFL learners' vocabulary acquisition?

2. Does dual version reading comprehension improve Iranian EFL learners' receptive knowledge of vocabulary?

3. Does dual version reading comprehension improve Iranian EFL learners' productive knowledge of vocabulary?

4. Does dual version reading comprehension improve Iranian EFL learners' ability to give a synonym for the selected words?

\section{Methodology}

\subsection{Participants}

The participants of the present study were two classes of the second- grade EFL learners ( $n=100)$, ages 18 to 29 years old. All the subjects had intermediate competence in English. This was determined by their classwork and homework assignments and also the paper- based version of the Test of English as a Foreign Language (TOEFL).This study was conducted in a medium-sized private language institute in Lahijan, Guilan province, Iran. All participants were male and shared Giuliani as their first language. The participants were seldom exposed to English and had very little opportunity to use English outside classrooms. The experimental group subjects were initially told that they would take part in a vocabulary-learning strategy program in which they would read two basic and advanced versions of the same text in each treatment session and by making a text comparison between them, they were to try to infer the meanings of any unknown words.

As for the implementation of the study, the instructor was the researcher himself. He was a non-native English teacher with almost ten-year experience in teaching English in language institutions and universities. One reason why the researcher became the instructor was that he was the designer of the entire process of implementing so he had full understanding of how to conduct this study smoothly and correctly.

\subsection{Instruments}

The instruments in this study included ten basic and advanced versions of reading articles prepared to read in class for the subjects of the experimental class and 4 types of tests. First, a vocabulary multiple-choice test was designed. Secondly, we checked learners' receptive knowledge of vocabulary items through a recognition test. Further, in order to elicit learners' vocabulary abilities in free production, we employed an essay test and finally, we also examined learner's abilities to give a synonym for the newly learned words through a production test. It should be mentioned that we developed a pre and post versions of all types of the above -cited tests. As for the two test periods, the pretests 
gauged learners' initial vocabulary abilities and the posttests aimed to measure if any vocabulary growth was available after the treatment sessions.

The vocabulary tests contained 30 test items and it required the test-takers to choose the correct answer. The allocated time for the vocabulary test was 25 minutes. The correct item was given one point.

The vocabulary recognition test which aimed to measure learners' receptive knowledge of words contained 25 test items and it required the test-takers to pick the correct words which match the corresponding definitions. The allocated time for the recognition test was 12 minutes. The correct item was given one point.

Concerning the essay test which aimed at investigating learning outcomes in written production, we selected a topic and asked the learners to write an essay and use the words which have been provided in a box. In fact the selected words were those which have been studied by them throughout the main study. We asked the learners to focus on their lexical use rather than the construction of their writing content and organization. Learners were required to finish a writing 200 -to-250 word essay with pen and paper in class within 30 minutes

Finally in order to examine learners' ability to remember the synonymous words which have been in the basic and advanced versions of the texts, we designed a production test and asked learner to write a synonym for each of the words. This test contained 20 words and learners were required to finish it within 15 minutes. One point was given for each correct answer.

\subsection{Reliability and validity}

The reliability for vocabulary multiple-choice test and vocabulary recognition test were calculated through KR-21 formula. The correlation coefficients for pre and post vocabulary multiple-choice tests turned to be 0.75 and 0.70 . As with recognition, the analyses of reliability for the vocabulary recognition pre and posttests yield the correlation of 0.74 and 0.78 . Regarding the validity, it was also estimated for all tests. We calculated the amount of correlation coefficient between our newly- developed tests and the subtest (looking at vocabulary part) of a valid test. This showed that the correlation coefficient were $0.70,0.74$ and $0.71,0.70$ for pre and post vocabulary multiple-choice tests and for vocabulary recognition pre and posttests. Furthermore, we also calculated the amount of correlation coefficient of the newly-developed tests and the other subtests part (grammar, pronunciation, reading, and writing) of a valid test. As expected, the result showed that since each two subtests were indeed testing different traits or skills, the correlation between our newly-developed tests and other subtests was low.

\subsection{Procedure}

This study uses a quasi-experimental comparison group design with pre- post tests. The experimental sequence of the study will be done over a period of approximately 2 months. Two classes will be randomly assigned to two groups which include (EG) and (CG). One week prior to the first treatment session all the participants took the pre-tests. Then, the experimental groups went through the treatments. The experimental treatment consisted of ten sessions. The second treatment session took place a full week after the first treatment session and the tenth treatment session was followed by the post-tests.

The first round of the test for the pretest was administered to both experimental and control classes in two periods of the same day. When we found that there were no significant differences based on the participant pretests scores, we went through the main phase of the study. In each treatment session the researcher distributed the advanced version of the reading article to the subjects and asked the subjects to read the article for ten minutes. Later, the researcher distributed the basic version of the same text among the participants and asked them to read the basic version and make a comparison between the implementation of the synonymous words in each version in order to make the input passages more comprehensible for themselves. In fact some words in advanced version of the text were then changed into substitute words in the basic version of the same text.

In other words, in each of these reading comprehension worksheets, the same story is told, but with two versions: one that is basic, and one that is more advanced. This allows students to make direct comparisons between the advanced version to the more basic one, and makes for a powerful learning experience.

\section{Result and Discussion}

\subsection{Statistical analysis of T- Test of vocabulary test}

In this section, the results of the students' performance on the vocabulary tests are analyzed and the findings concerning the research question 1 are also presented and examined.

Research Question 1: Does dual version reading comprehension improve Iranian EFL learners' vocabulary acquisition?

In terms of the performance on the two vocabulary tests, the result showed that there were not any significant differences between the experimental and control groups at the beginning of the study $t(100)=0.321, p>0.05$. However, the difference reached a significant level between the experimental and control groups $t(100)=2.467, \mathrm{p}>0.05$ according to the results of the vocabulary scores in the posttest. This means that dual version reading comprehension enhanced vocabulary proficiency of the students in the experimental group at the end of the study. In order to further examine the results of the vocabulary tests of the two groups, the means and standard deviation are shown in Table 1. 
Table 1. Descriptive statistics for vocabulary test scores

\begin{tabular}{|c|c|c|c|c|c|}
\hline \multirow[b]{2}{*}{ Group } & \multirow[b]{2}{*}{$\mathbf{n}$} & \multicolumn{2}{|c|}{ Pretest } & \multicolumn{2}{|c|}{ Posttest } \\
\hline & & Mean & SD & Mean & SD \\
\hline EG & 52 & 5.16 & 2.92 & 6.92 & 2.07 \\
\hline CG & 48 & 5.10 & 2.35 & 5.50 & 2.33 \\
\hline
\end{tabular}

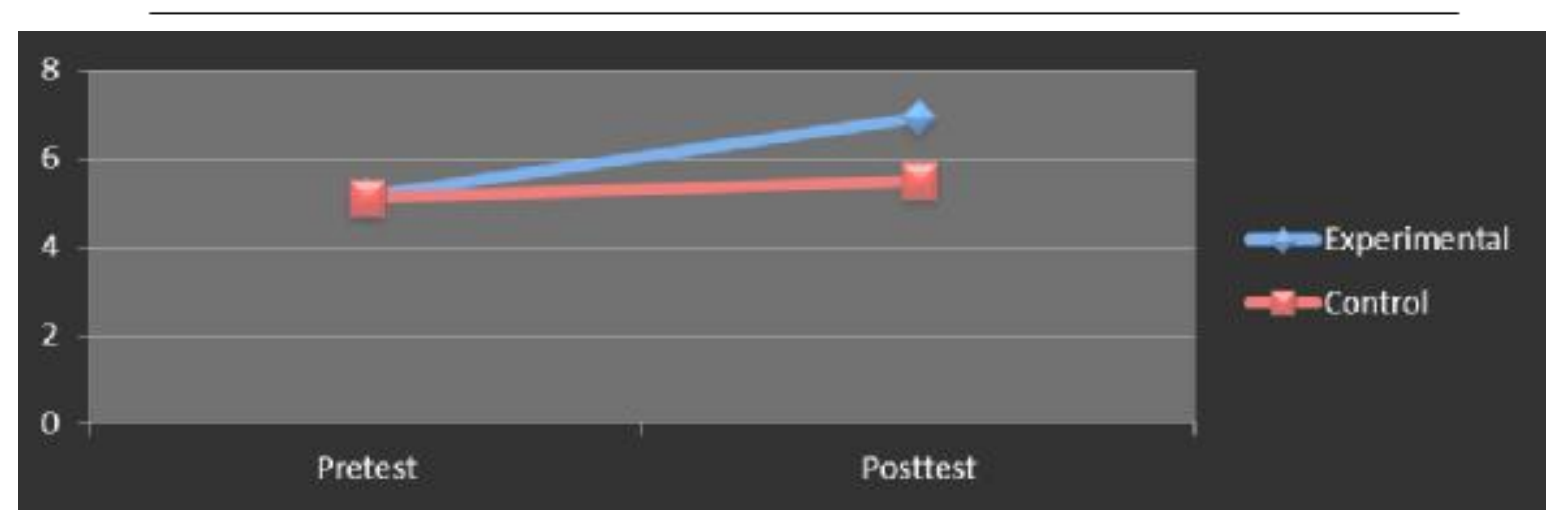

Figure 1.1 Mean scores graph of vocabulary test by the two groups

With regard to the integral performance, the students in the experimental group performed better than those in the control class after the posttest. This means that the vocabulary strategy dual version reading comprehension- indeed facilitated the students' English learning. Further investigation of the effects on their vocabulary learning indicates that the students in the experimental class indeed made great improvements on their vocabulary tests. This result corresponds to Frazer's study (1999) that lexical inferencing can facilitate vocabulary learning. Further, it is also in agreement with the study of Nagy et al. (1985) that vocabulary gain in terms of learning from context is existent. According to the results, it was found that the experimental students experienced significant differences. Because we have selected the intermediate EFL learners in our study, this result corresponds to Hsu's study (2004) in that low- and mid-proficiency students can benefit more from the vocabulary learning strategy instruction than high-proficiency students. Although we did not examine the impact of the treatment on the high proficiency level students but our claim might be based on the fact that that high- proficiency students originally possessed better ability to guess from context and language knowledge (Bengeleil \& Paribakht, 2004; Hsu, 2004), leading to vocabulary gain in less obvious.

\subsection{Statistical analysis of T-Test of recognition test}

In order to assess students' receptive knowledge of vocabulary, students' scores on the pre and post recognition tests were also analyzed.

Research Question 2: Does dual version reading comprehension improve Iranian EFL learners' receptive knowledge of vocabulary?

A $t$-test test was performed to make sure there were no pre-treatment differences among the experimental and control groups $t(100)=0.047, p>0.05$ for recognition test. Based on the results indicating that the two groups were equal, the differences in the post-tests among the groups, if any, could be due to the respective treatment that each group received. Another t-test done on the two groups' scores in the post recognition test showed that there was a significant effect for treatment on the post-treatment recognition test scores test $t(100)=2.097, p<0.05$.

Table 2. Descriptive statistics for vocabulary recognition test scores

\begin{tabular}{lcccccc}
\hline & & \multicolumn{2}{c}{ Pretest } & & \multicolumn{2}{c}{ Posttest } \\
\cline { 3 - 4 } \cline { 5 - 6 } Group & $\mathrm{n}$ & Mean & SD & & Mean & SD \\
\hline EG & 52 & 6.10 & 2.02 & & 7.63 & 2.11 \\
CG & 48 & 6.39 & 2.15 & & 6.50 & 2.45 \\
\hline
\end{tabular}

According to the experimental and control group results on the posttest, the treatment had a positive effect on the experimental group students. In other words, in their vocabulary recognition test performance, an effect was evident. 


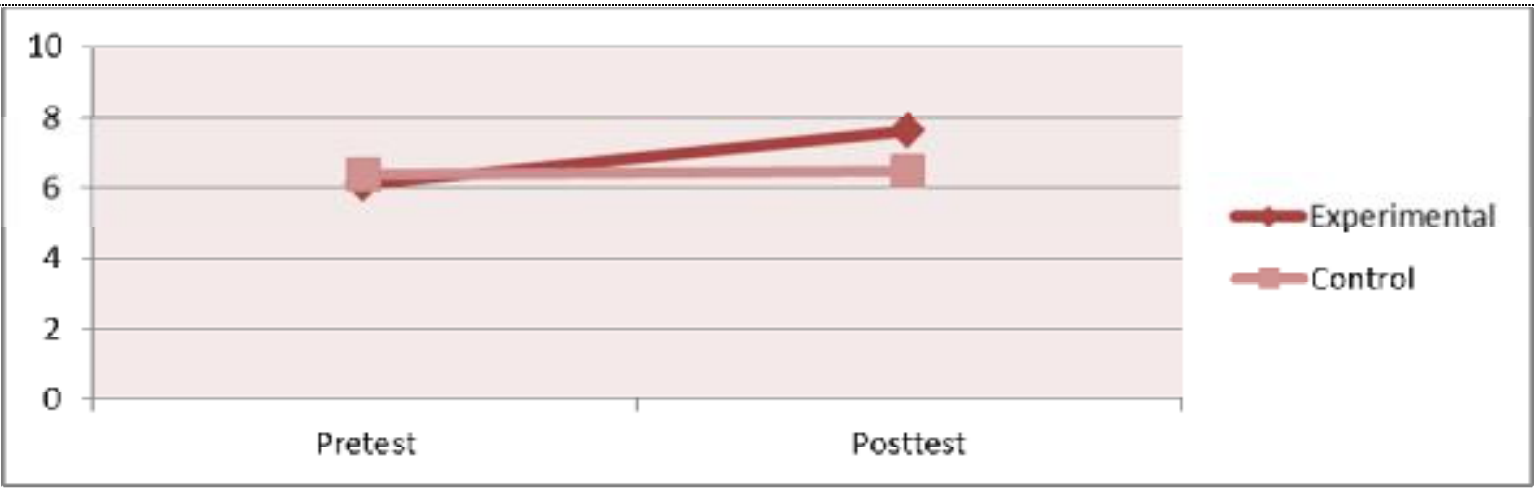

Figure 1.2 Mean scores graph of vocabulary recognition test by the two groups

Concerning the role of receptive knowledge of vocabulary, (Coxhead, 2000; Nation, 2006) claim that expanding the L2 learners' receptive academic vocabulary has been advocated to assist the learners to comprehend the academic texts. However with respect to the whole performance in terms of receptive knowledge of vocabulary, significant results occurred in the experimental group in this study. Because we tried to investigate the impact of dual version reading comprehension which is a kind vocabulary learning though interesting ways of reading texts comparison, this result can correspond to the fact that this type of vocabulary learning through text comparison provided the learners with the equal opportunities of processing the target words receptively to gain better control over the words. In other words, the experimental group showed substantial gains in definitional knowledge in the posttest.

\subsection{Statistical analysis of T-Test of production test}

Research Question 3: Does dual version reading comprehension improve Iranian EFL learners' productive knowledge of vocabulary?

In order to elicit learners' vocabulary abilities in free production, the two groups still showed no differences $t(100)=$ $0.735, p>0.05$ in version 1 (pretest). However, the students' scores in version 2 (posttest) of essay test indicated that the dual version reading comprehension group students in the experimental group performed better than those in the control group $t(100)=2.715, p<0.05$ and the differences between the experimental and control groups essays were significant. In other words, the findings from the statistical analysis suggest that the experimental group improved and made more gains from the pre-test to the post-test.

Table 3. Descriptive statistics for vocabulary production (short essay) test scores

\begin{tabular}{lllllll}
\hline & & \multicolumn{2}{c}{ Pretest } & & \multicolumn{2}{c}{ Posttest } \\
\cline { 3 - 6 } Group & n & Mean & SD & & Mean & SD \\
\hline EG & 52 & 12.96 & 0.889 & & 16.22 & 1.444 \\
CG & 48 & 12.39 & 0.315 & & 12.50 & 0.445 \\
\hline
\end{tabular}

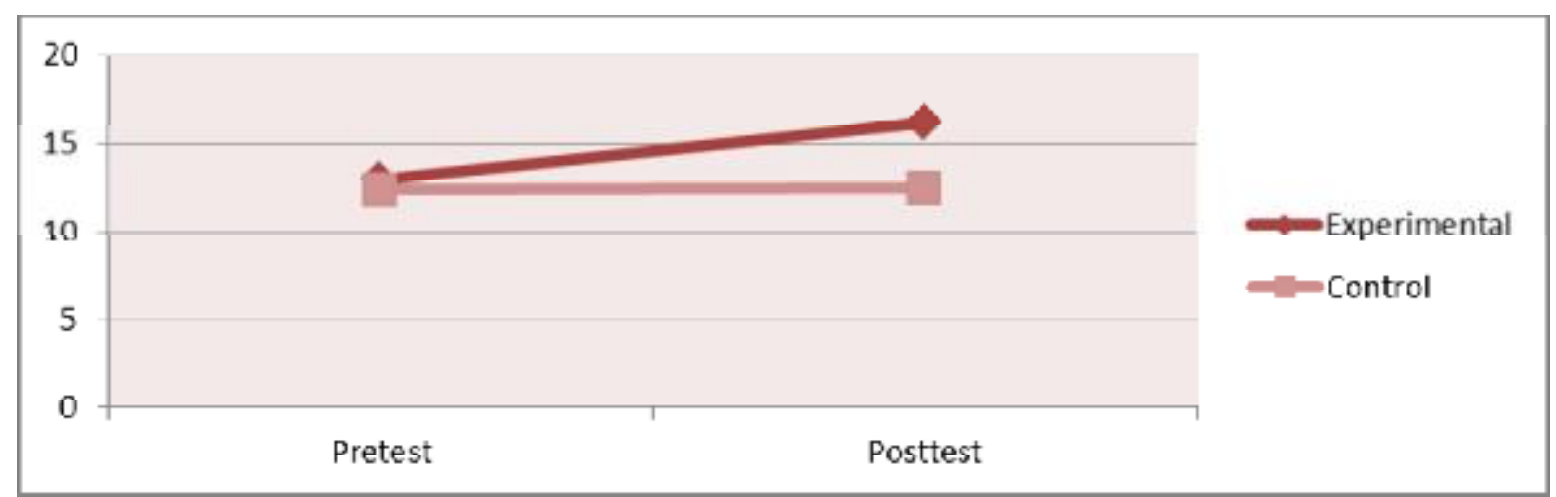

Figure 1.3 Mean scores graph of vocabulary production test by the two groups

This study proved that our specific type of treatment may have aroused the learners' attention to compare different words in different basic and advanced versions of texts that lead to some gains in experimental group students' better words usage across the essay tests and learners were able to transfer their receptive knowledge into their productive knowledge(Huang, H. T., 2004; Lee, 2003). In other words, the treatment allowed the experimental group students to possess sufficient English and vocabulary knowledge to incorporate the words in their essay tests. The adequate lexical productive ability enables the learners to effectively convey their own ideas rather than studying as readers who can only 
receive the messages passively. First, the reading-to-write task encourages the learners to process the target words with the peripheral or focal attention. More "involvement load "thus will be induced, when the learners try to manipulate their lexical knowledge for task completion (Laufer \& Hujstijn, 2001). In other words, the learners will be motivated in finding the appropriate words by the form-meaning mapping to tackle the tasks.

\subsection{Statistical analysis of T-Test of synonym test}

Research Question 4: Does dual version reading comprehension improve Iranian EFL learners' ability to give a synonym for the selected words?

In order to examine learners' ability to provide a synonym for some of the words, the subjects' individual scores in pretest were compared by using a t-test. The comparison of scores showed that no statically significant difference was found at the beginning of the experiment through scores analysis $t(100)=0.735, p>0.05$. The mean scores of the posttest obtained by the experimental and control groups were compared again. It was found that the experimental group outperformed the control group again $t(100)=2.621, p<0.05$.

Table 4. Descriptive statistics for vocabulary synonym test scores

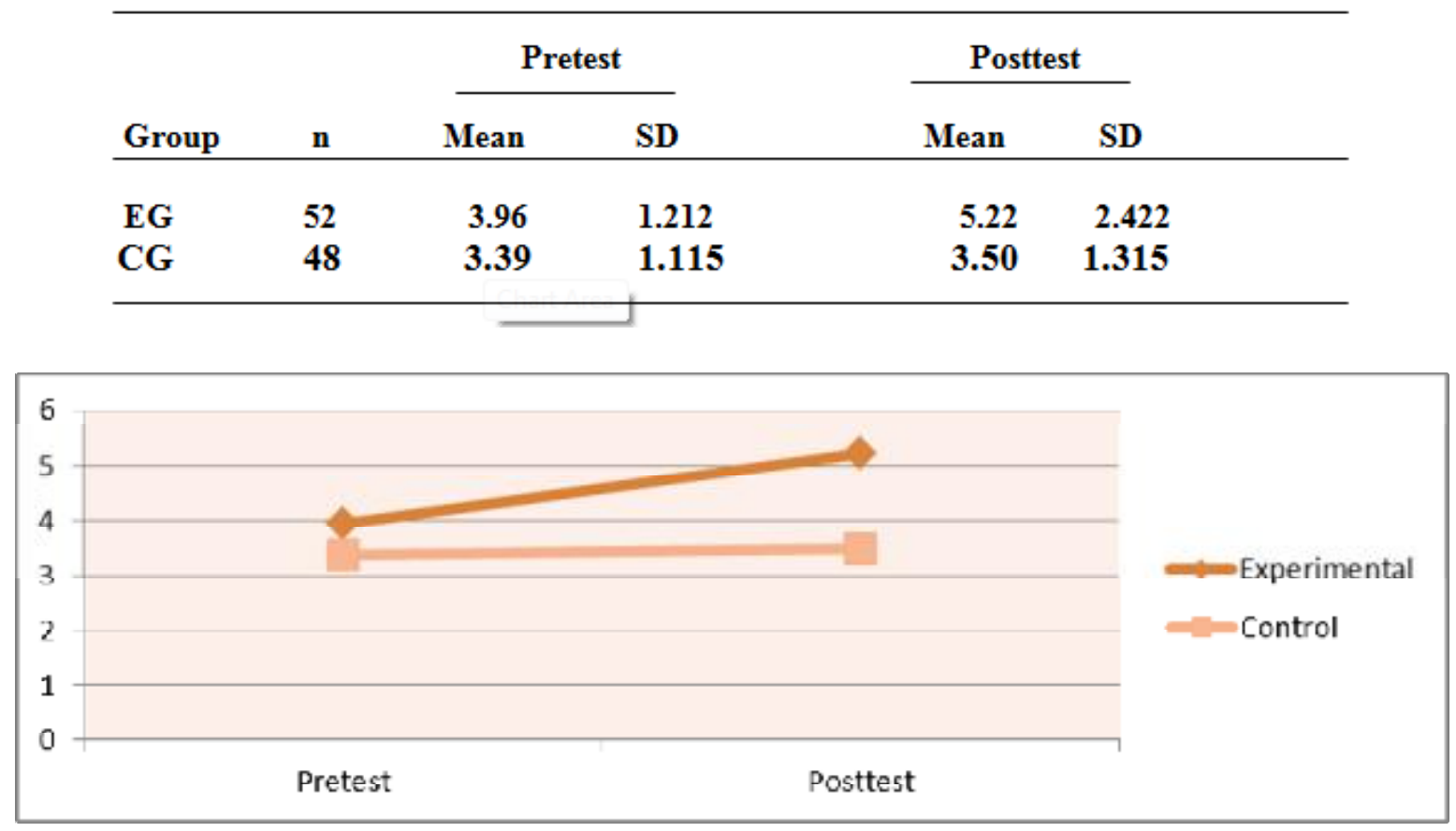

Figure 1.4 Mean scores graph of vocabulary synonym test by the two groups

Providing the opportunities of the basic and advanced version of text within the study also helped the experimental group students improve their ability to retain synonym words. In fact intensive exposure to a number of target words in the basic and advanced texts of reading aided their memorization. The results appear to indicate the importance observation of words in basic and advanced texts or different contexts in promoting depth of processing which result in higher retention rates.

\section{Conclusion}

This study aimed to examine the effects of the dual version reading comprehension on vocabulary rates of the intermediate EFL students. The researcher chose two of his own classes to conduct the study: one was the experimental class and the other was the control. Before the main study was implemented, four types of the pretests were given. Next, all of the subjects in the experimental class received the dual version reading comprehension strategy. After the treatment sessions, the posttests were given. After collecting all of the data and analyzing the results, the researcher makes the conclusions. Besides, some major findings were summarized in accordance with the three research questions proposed in Chapter One. First, with regard to the first research question concerning whether the dual version reading comprehension had any significant effect on students' vocabulary acquisition scores, the findings indicate that the experimental class scores reached statistical significance in terms of vocabulary acquisition. The result implies that teaching students how to analyze new words in different basic and advanced contexts can enhance their vocabulary acquisition. In fact the treatment draws learners' attention to new words in basic and advanced versions of the text. Second, in respect of the second research question concerning the influence of dual version of reading comprehension on the subjects' receptive knowledge of vocabulary, the findings indicate that the subjects benefited in their receptive knowledge of vocabulary acquisition. On the other hand, providing and processing enough language information, and knowing word meanings in context the experimental group subjects did see a significant effect in terms of their receptive power of words. Research question three attempted to determine whether dual version reading comprehension will influence students' productive knowledge of vocabulary. The answer was 'yes'. It was shown that experimental 
group outperformed the control group because the dual version reading comprehension allowed students to process the words in great depth, shape their receptive knowledge and finally transfer it to the productive knowledge. Regarding the last research question, it was shown that because experimental learners compared and contrasted the basic and advanced version of some of the target words, it not only helped them comprehend the text effectively but also had an equivalent or synonym for some key words in the text the lead to their retention of synonymous words. To sum up, It is also important to notice, the results of this experiment suggest that a teacher would be able to greatly increase the chance that a word would be learned simply by drawing learners' attention to it through dual version reading comprehension which don't greatly increase the amount of preparation time needed. The preliminary results of the present research would be in some ways related pushed-output techniques because students have to regularly compare the contexts of the two texts and focus on the basic version of advanced words in order to find out the meanings of the difficult words. This technique lead students to greater gains in depth of knowledge of individual words rather than the equal or greater number of words, albeit at a shallower depth.

\subsection{Pedagogical Implications}

As shown in the major findings of the study, the students receiving the dual version reading comprehension seemed to have made significant progress in different terms of vocabulary acquisition. Thus, based on the findings, some pedagogical implications are suggested. First, besides explicit vocabulary teaching in class, teachers can apply the dual version reading comprehension during their classes. It will increase learners' chances of inferring and true guessing of words more successfully and also increase their reading comprehension rates. In fact when teachers provide the basic and advanced version of the same texts, learners will process the texts effectively, try to discover the meanings of unknown words on their own and through the aid of the texts, become familiar with the real context and use of words, find out the synonymous words, and these focuses on words and texts will result in better retention of them over time. In other words, when learners specially beginning and intermediate learners realize that to what extent they can analyze the texts on their own, it will improve their perceiving view of themselves as the source of action and increasing their self efficacy power in vocabulary and reading comprehension.

\section{References}

Bengeleil, N. F., \& Paribakht, T. S. (2004). L2 reading proficiency and lexical inferencing by university EFL learners. The Canadian Modern Language Review, 61(2), 225-249.

Clarke, D. F., \& Nation, I. S. P. (1980). Guessing the meanings of words from context: Strategy and techniques. System, $8(3), 211-220$.

Coady, J. (1993). Research on ESL/EFL vocabulary acquisition: Putting it in context. In T. Huckin, M. Haynes \& J. Coady (Eds.), Second language reading and vocabulary learning (pp. 3-25). Norwood, NJ: Ablex.

DeCarrico, J. S. (2001). Vocabulary learning and teaching. In M. Celce-Murica, (Ed.), Teaching English as a second or foreign language ( $3^{\text {rd }}$ ed., pp. 285-299). Boston, MA: Heinle \& Heinle.

Frazer, C.A. (1999). Lexical processing strategy use and vocabulary learning through reading. Studies in Second Language Acquisition, 21, 225-241.

Gass, S. (1999). Discussion: Incidental vocabulary learning. Second language reading and vocabulary learning, 21, 319-333.

Huckin, T., \& Coady, J. (1999). Incidental vocabulary acquisition in a second language. Studies in Second Language Acquisition, 21, 181-193.

Kelly, P. (1991). Lexical ignorance: The main obstacle to listening comprehension with advanced foreign language learners. IRAL, 29, 135-149.

Krashen, S. (1989). Language acquisition and language education. London: Prentice Hall.

Laufer, B. (1997). The lexical plight in second language reading. In J. Coady \& Y. Huckin (Eds.), Second language vocabulary acquisition (pp. 21-34). Cambridge: Cambridge University Press.

Nagy, W. E., Herman, P. A., \& Anderson, R. C. (1985). Learning words from context. Reading Research Quarterly, 20, 233-253.

Nation, I. S. P. (1990). Teaching and learning vocabulary. New York: Newberry House.

Nation, I. S. P., \& Waring, R. (1997). Vocabulary size, text coverage and word lists. In N. Schmitt \& M. MaCarthy (Eds.), Vocabulary: Description, acquisition, and pedagogy (pp. 6-19). Cambridge: Cambridge University Press.

Nation, P. (2001). Learning vocabulary in another language. Cambridge: Cambridge University Press.

Oxford, R. L. (1990). Language learning strategies: What every teacher should know. Boston: Newbury House.

Schmitt, N. (2000). Vocabulary in language teaching. Cambridge: Cambridge University Press.

Thornbury, S. (2002). How to teach vocabulary. London: Longman.

Wilkins, D. A. (1972). Linguistics in language teaching. London: Edward Arnold Williams, R. (1985). Teaching vocabulary recognition strategies in ESP reading. ESP Journal, 4, 121-131. 
Yu-Kuo, H. (2008). The effect of Lexical Inferencing on Vocabulary Acquisition and Reading Comprehension. Unpublished MA thesis, National Chung Cheng University, Japan.

Zimmerman, C.B. (1997). Historical trends in second language vocabulary instruction. In J. Coady and T. Huckin (Eds), Second Language Vocabulary Acquisition. Cambridge: Cambridge University Press.

\section{Appendix \\ Directions: First read the basic version of the story below. Next, read the advanced version of the same story. Then, try to answer the questions about the story.}

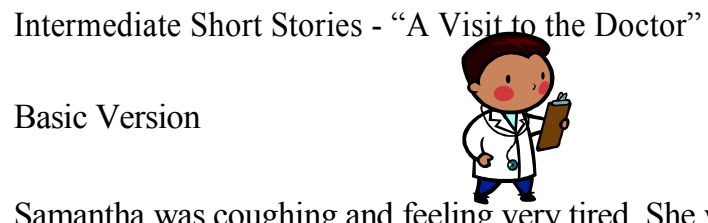

Samantha was coughing and feeling very tired. She was sick. She wanted her mother to take her to the doctor's office. "Mom, I am feeling very sick," she said. "I think I need to take you to the doctor," her mother said. They got in the car and drove to the doctor's office. The doctor looked carefully at the back of her mouth. He also asked her some questions about how she was feeling."It looks like you have a bad cold. You will need some medicine to make you feel well again." "Ok, thank you doctor," said Samantha. Then Samantha and her mom went to the drugstore to get the drug. She took the medicine when they got home. In a few days she felt better.

\section{Advanced Version}

Samantha was coughing and feeling very tired. She was sick. She wanted her mother to take her to the doctor's office. "Mom, I am feeling very sick," she said. "I think I need to take you to the doctor," her mother said. They got in the car and drove to the doctor's office. The doctor examined her throat. He also asked her some questions about how she was feeling. "It looks like you have a bad cold. You will need some medicine to make you healthy again." "Ok, thank you doctor," said Samantha. Then Samantha and her mom went to the pharmacy to get the medicine. She took the medicine when they got home. In a few days she felt better.

Questions:

1. What was wrong with Samantha?

2. What did Samantha's mother decide to do about Samantha?

3. What did Samantha get at the pharmacy?

Vocabulary:

To find word definitions: First, find the word in the advanced version of the story. Then, compare this part of the advanced version of the story to the same part of the basic version of the story. This will give you a general definition of the word.

1. What does “examined” mean? (paragraph 3, sentence 2)

2. What does "throat" mean? (paragraph 3, sentence 2)

3. What does "healthy" mean? (paragraph 4, sentence 2)

4. What does "pharmacy" mean? (paragraph 5, sentence 1) 